\title{
Human pseudomyiasis caused by Eristalis tenax (Linnaeus) (Diptera: Syrphidae) in Goiás
}

\author{
Pseudomiíase humana causada por Eristalis tenax \\ (Linnaeus) (Diptera: Syrphidae) em Goiás
}

\author{
Marco Tulio A. Garcia-Zapata ${ }^{1}$, Edson Sidião de Souza Júnior ${ }^{1}$, \\ Fernando Freitas Fernandes ${ }^{2}$ and Sônia F.O. Santos ${ }^{1}$
}

\begin{abstract}
The objective of the present work was to register the first proven cases of human pseudomyiasis due to Eristalis tenax in Goiás State, Brazil, underscoring their clinical manifestations and direct relationship with hygiene. The taxonomic identification of the instars was done according to the descriptions and keys presented by James (1947), Hartley (1961) and Guimarães \& Papavero (1999). Two cases were observed. In both cases there was no evidence of apparent mental disturbance. The clinical picture of these cases was self limited. The water supply, sewer system, socioeconomic level and habits of the suspect species of the flies are criteria that should be investigated.
\end{abstract}

Key-words: Diptera. Syrphidae. Eristalis tenax. Pseudomyiasis.

\section{RESUM0}

0 presente trabalho visa registrar os primeiros casos evidenciados de pseudomiíases humanos por Eristalis tenax no estado de Goiás, Brasil, destacando suas manifestações clínicas e suas relações diretas com os hábitos higiênicos. A identificação taxonômica das larvas foi realizada com base nas descrições e chaves apresentadas por James (1947), Hartley (1961) e Guimarães \& Papavero (1999) . Observaram-se dois casos. Em ambos não havia evidência de pertubações mentais claras. 0 quadro clínico de ambos os casos era mesmo limitado. 0 abastecimento de água, o nível sócioeconômico e 0 hábito das espécies das moscas são critérios que devem ser considerados na investigação.

Palavras-chaves: Diptera. Syrphidae. Eristalis tenax. Pseudomiíases.

Gastrointestinal myiasis caused by the cosmopolitan drone fly Eristalis tenax (Diptera: Syrphidae) is classified as pseudomyiasis, given the biology of the fly and thatitoccurs in an accidental manner. Its presence, in the surface of the digestive tract is responsible for the pathologic physiology, in general of lesser gravity than thatcaused by the obligatory or facultative parasites ${ }^{6}$.

The genus Eristalis (Linnaeus) was designated commonly as Tubifera (Meigen), and some researchers have also denominated it Eristalomyia. The simple observation of the family rat-tailed maggot (long respiratory siphon) characteristic in larvae instars has incited some researchers to the diagnosis of $\mathrm{E}$. tenax. Though, this is not a pathognomonic characteristic, or exclusive to this species or its genus. Thus, many incorrect records and inaccurate descriptions result from this extrapolation ${ }^{3}$.

The larvas of E. tenax are extremely resistant to adverse conditions of pressure, heat and salinity ${ }^{5}$. They live in water polluted by feces, sewage, liquid excrements and organic materials in decomposition, including carcasses. Occasionally they can be found in relatively clean water ${ }^{3}$, however, the occurrence of $\mathrm{E}$. tenax larvae in stagnated waters indicates a high degree of pollution ${ }^{1}$.

Gastrointestinal pseudomyiasis presents unspecific symptoms and its clinical aspects vary in agreement with the

1. Unidade de Protozoologia do Instituto de Patologia Tropical e Saúde Pública da Universidade Federal de Goiás, Goiânia, G0. 2. Laboratório de Artropodologia Médica e Veterinária do Instituto de Patologia Tropical e Saúde Pública da Universidade Federal de Goiás, Goiânia, G0.

Órgão financiador: CNPq

Address to: Dr. Marco Tulio A. Garcia-Zapata. Caixa Postal 12.911, Setor Leste, Vila Nova, 74643-970 Goiânia, G0, Brasil.

Fax: 5562 521-1839

e-mail: zapata@ iptsp.ufg.br

Recebido para publicação em 8/10/2003

Aceito em 16/11/2004 
number of eggs or larvae ingested, with the affected organ and the fly species ${ }^{4}$.

The present work aims to register the first proven cases of gastrointestinal human pseudomyiasis in Goiás State, Brazil, underscoring their clinical manifestations and direct relationship with the hygiene habits that were responsible for initiating the dynamic process of the pathologic physiology by ingesting waters or fruits contaminated with larvae of this fly.

In this paper, the taxonomic identification of the instars was accomplished in the Laboratory of Medical and Veterinary Arthropodology (LAMV) at the Institute of Tropical Pathology and Public Health (IPTSP), based on the descriptions and keys presented by James ${ }^{3}$, Hartley ${ }^{2}$ and Guimarães \& Papavero ${ }^{1}$.

\section{CASE REPORTS}

Case 1. Female patient, 11 months of age, natural and resident in the municipality of Goiânia-GO. The mother refers that after having ingested a great amount of mangos and guavas that had fallen under a tree and were in a state of decomposition, in a small farm near to where she lives, the child presented intense pasty diarrhea associated with abdominal pain and presence of four larval instars in the diaper. Later, the child's diaper with feces containing the larvae was shown to the pediatrician during a medical consultation. This material was forwarded to the LAMV for diagnosis and appropriate handling of this pathology. The specimens were washed in distilled water, then fixed in $70 \%$ ethanol and subsequently identified as pre-pupae of $\mathrm{E}$. tenax (Figure 1).

Case 2. Male patient, 27 years of age, natural and resident in the municipal district of Rio Verde-G0 and a traveling salesman. The frequent route of his trips was to São Paulo-SP, Recife-PE, and cities of the Goiás state interior. In the last four months he presented a non-mucosanguineous pasty diarrhea, associated

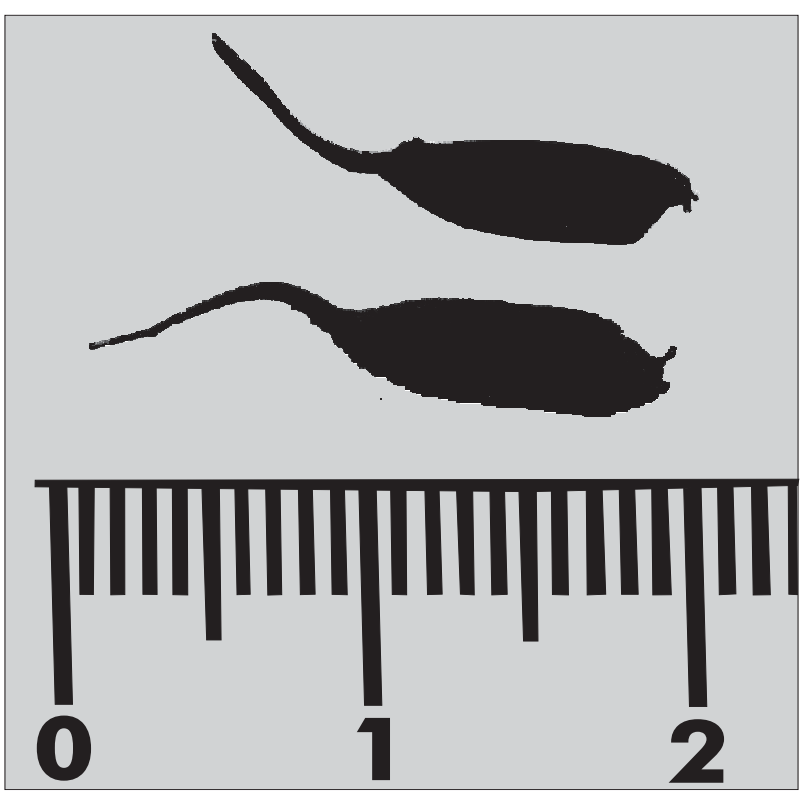

Figure 1 - Pre-pupae of Eristalis tenax reported in case 1. to colic, nausea, insomnia and weakness, that intensified, especially the diarrhea, until elimination of the larva. In the period he manifested neither fever nor vomits. The larva was detected by the patienthimself after a diarrhea episode, the sample was conserved in $70 \%$ alcohol and directed by a diagnosis center of the Unified Health System ( SUS) network laboratories in Goiânia-G0 for analysis in this LAMV. The larva was identified as third instar E tenax ( Figure 2).

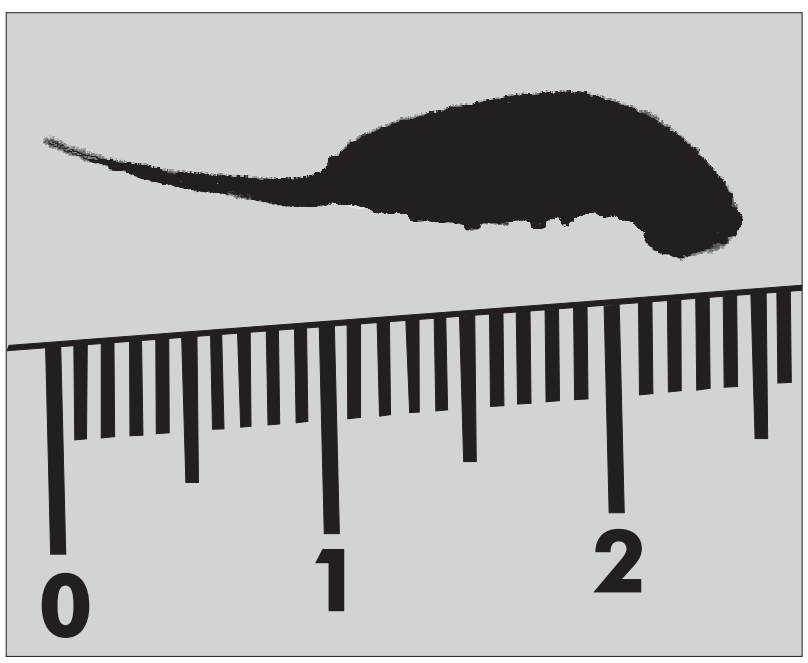

Figure 2 - Third-stage larva of Eristalis tenax reported in case 2.

In both cases there was no evidence of apparent mental disturbance.

\section{DISCUSSION}

In case 1, the patient's age, without due supervision by an adult explains the non discrimination of the foodstuffs ingested, given the difficulties in selecting adequate fruit. It is believed that the transformation of mature larvae into prepupae occurred externally, due to the permanence of these in direct contact with the feces and diaper material, during the period between defecation and forwarding for exam under a stereoscopic microscope at the LAMV.

In case 2 , the patient did not practive appropriate hygiene habits, nor was concerned about the origin of foodstuffs and water consumed during his trips, which would explain the accidental origin of this infestation. The clinical picture of both cases was self limited, the gastrointestinal signs and symptoms ceased after spontaneous elimination of the larvae.

The water supply, sewer system, socioeconomic level together with the habits of the suspect species of the flies are factors or criteria that should be considered in the evaluation of this pathology. Furthermore, in other countries, the ingestion of food or water contaminated by eggs or larvae has been considered to be the main source of infestation by $E$. tenax ${ }^{4}$.

\section{ACKNOWLEDGEMENTS}

The authors thank Prof. Miguel Alípio Vieira (in memoriam) for referral to LAMV of the first clinical case in Goiás and biological samples for respective specific diagnosis. 


\section{REFERENCES}

1. Guimarães JH, Papavero N. Generalities about myiasis in the Neotropical Region. In: Guimarães JH, Papavero N (eds) Myiasis in man and animals in the neotropical region - bibliographic database. Editora Plêiade, São Paulo, p. 16, 1998.

2. Hartley JC. A taxonomic account of the larvae of British Syrphidae. Proceedings of the Zoological Society of London 136: 505-573, 1961.
3. James MT. The flies that cause myiasis in man. United States Department of Agriculture, Miscellaneous publication ㄲo 631, Washington, 1947.

4. Kun M, Kreiter A, Semenas L. Myiasis gastrointestinal humana por Eristalis tenax. Revista de Saúde Pública 32: 367-369, 1998.

5. Thompson FC. Revision of the Eristalis flower flies (Diptera: Syrphidae) of the Americas south of the United States. Proceedings of the Entomological Society of Washington 99: 209-337, 1997.

6. ZumptF. Myiasis in man and animals in the Old Word. Butterworths London, 1965. 